\title{
A National Survey of Parent Perspec- tives on Use of Patient Portals for Their Children's Health Care
}

S.J. Clark'; L.E. Costello'; A. Gebremariam; K.J. Dombkowski ${ }^{1}$

${ }^{1}$ Child Health Evaluation and Research Unit, University of Michigan

\author{
Keywords \\ Patint portal, meaningful use, parent-provider communication
}

\section{Summary}

Objectives: To assess parents' current utilization and future willingness to use patient portals to interact with their child's health care provider.

Methods: A cross-sectional survey of a nationally representative sample of US parents was conducted using an established online panel. Bivariate analyses assessed associations between current utilization and future willingness to use patient portals, parental concerns, and demographic variables.

Results: Among the 1,420 parent respondents, $40 \%$ did not know whether their child's health practice offers the option of setting up a patient portal for their child. Of the $21 \%$ of parents who reported being offered the option of setting up a patient portal for their child, $59 \%$ had done so. Among parents who had the option but chose not to set up a patient portal for their child, lack of time and low perceived need were the main reasons cited. Current use and likelihood of future use was highest for viewing lab results and immunization records. The most common concern about patient portals was the security of the child portal system.

Conclusions: Current use of patient portals by parents is low. Only about half of parents currently using or likely to use a portal perceive value in using portals for certain tasks, which suggests that providers will need to continue traditional communication mechanisms to reach their entire patient population.

\section{Correspondence to:}

Sarah J Clark

300 North Ingalls, 6 E06

Ann Arbor, MI 48109-5456

Phone: (734) 936-8832

Fax: (734) 764-2599

Email: saclark@umich.edu

\author{
Appl Clin Inform 2015 ;6: 110-119 \\ http://dx.doi.org/10.4338/ACl-2014-10-RA-0098 \\ received: November 5, 2014 \\ accepted: January 15, 2015 \\ published: February 25, 2015 \\ Citation: Clark SJ, Costello LE, Gebremariam A, Domb- \\ kowski KJ. A national survey of parent perspectives on \\ use of patient portals for children's health care. Appl \\ Clin Inf 2015; 6: 110-119 \\ http://dx.doi.org/10.4338/ACl-2014-10-RA-0098
}




\section{Background}

The federal Health Information Technology for Economic and Clinical Health (HITECH) Act establishes financial incentives for physicians who implement electronic health records (EHR) systems and utilize them in a meaningful way to interact with patients [1]. To qualify for incentives under the "Meaningful Use" program, physicians must meet certain criteria, defined by the Centers for Medicare and Medicaid Services (CMS), in several domains. Under the domain of engaging patients and families in their health care, one criterion is to provide patients with the ability to electronically view, download, and transmit their health information,[2] such as through the use of patient portals [3].

Patient portals are personal, secure web-based connections that allow patients or parents to interact electronically with a health care practice for activities such as viewing their medical records, requesting appointments or medication refills, and sending messages to providers [4]. Despite the significant HITECH incentives aimed at encouraging EHR adoption, it is unclear whether patient portals are likely to become a predominant mode of communication between physicians and patients and/or parents. The majority of published studies regarding patient portal use have focused mainly on adult patients [5-8]. Of the few studies examining parental use of patient portals for children, most included parents of children with chronic disease only[8-13] or small samples that are not nationally representative $[13,14]$. With these caveats in mind, existing studies of pediatric patient portal use by parents have shown sociodemographic disparities in portal enrollment and activation $[10,13,15]$ and some usability concerns [12]; on the other hand, portals have been perceived by parents as beneficial $[11,14]$ and have been associated with increased receipt of appropriate preventive services [14], though impacts on parent perceptions of their children's health care were mixed $[9,14]$.

\section{Objectives}

The purpose of our study was to assess parents' current utilization and future willingness to use patient portals to conduct business and patient care activities for their child.

\section{Methods}

\subsection{Study Design}

We conducted a cross-sectional, internet-based survey of a nationally representative sample of parents of children 0-17 years. The study was approved by the University of Michigan Medical School Institutional Review Board.

\subsection{Sample}

The survey was conducted in conjunction with the C.S. Mott Children's Hospital National Poll on Children's Health (NPCH), a recurring online survey of parents and non-parents.[15] The NPCH is conducted using the web-enabled KnowledgePanel ${ }^{\circledR}$ (GfK Custom Research LLC), a probabilitybased panel that is representative of the US population [16]. NPCH KnowledgePanel ${ }^{\varpi}$ surveys have explored a variety of health-related issues, as documented in many national peer-reviewed publications [e.g., 17-20].

The design for KnowledgePanel ${ }^{ø}$ recruitment begins as an equal probability sample with several enhancements to improve efficiency, such as oversampling in census blocks with high-density minority communities. Since 2009, GfK has recruited KnowledgePanel ${ }^{\circledR}$ participants by a random selection based mainly on residential addresses. Persons in selected households are then invited to participate in the web-enabled KnowledgePanel ${ }^{\varpi}$. For those who agree to participate who do not already have Internet access, a laptop and internet connection are provided at no cost to the participant; those who already have a computer and internet service use their own equipment. GfK develops 
demographic profiles for each panel member, and sends periodic emails inviting them to participate in surveys, using unique log-in information to access surveys online.

For this NPCH survey, the introductory email invited participation in a survey about child health and was targeted to panel members identified in GfK profile data as being a parent of one or more children aged 0-17 years; the authors had no direct contact with the sample. To reduce the effects of any non-response and non-coverage bias in the overall KnowledgePanel ${ }^{\circ}$ membership, GfK applies a pre-sampling post-stratification adjustment based on demographic distributions from the Current Population Survey (CPS).

The survey was pilot tested with a separate convenience sample of 100 KnowledgePanel ${ }^{\circ}$ members, and the final survey was fielded in June 2013.

\subsection{Survey Items}

Brief background information on patient portals was provided to parents: "A patient portal is a personal, password-protected internet connection to a health care practice. A patient portal would allow you to $\log$ in and exchange information with the health care practice specifically about your child(ren)." Parents were asked whether their child's usual health care practice offers the option of setting up a patient portal and, if so, if they have set up a portal for their child(ren). Parents who reported setting up a portal for their child were asked whether they had ever used the portal to conduct business tasks (schedule an appointment, update contact/insurance information, request reminders about child's upcoming appointment, request reminders to schedule child's next appointment or immunization) or patient care tasks (get advice regarding child's minor illness or injury, see/print a copy of child's immunization record, request a prescription refill for child, see results of child's lab tests, request referral for child). Parents who reported that they did not set up a portal were asked to choose a reason for not setting up the portal (no time, not good at technology, no need for patient portal, did not know I needed to set something up, other). Parents who did not report an option to set up a portal were asked how likely they would be to use their child's portal for business and patient care tasks in the future. All parents were asked to rate their level of concern (not concerned, somewhat concerned, very concerned) for a list of potential concerns about patient portals: someone could hack into the system and see my child's personal health information, I would not know which member of the office staff is answering my question, it may take too long to get a response to my questions or requests, and there's a greater chance of errors if my child doesn't see the doctor in person.

Parent demographics also were collected (i.e., age, gender, race/ethnicity, household income, education level, age of child(ren), type of practice where child(ren) receive routine health care, and whether any child has a chronic condition). Parents were considered to have a child with a chronic condition if they reported that $\geq 1$ child had ever been diagnosed by a doctor with one or more of the following conditions: allergies, asthma, attention deficit/hyperactivity disorder (ADD/ADHD), behavioral disorders, birth defects, depression, diabetes, heart problems, lung disease from prematurity, overweight/obesity, or seizures.

\subsection{Statistical Analyses}

GfK provided the study team with de-identified data, along with study-specific, Census-based poststratification weights used to adjust for the study's sample design and survey nonresponse, to ensure that study data are nationally representative.

Frequency distributions were calculated on all variables; chi-square tests were performed to assess the associations between key outcome measures (current utilization and future willingness to use patient portals, parental concerns) and key demographic variables (parent race/ethnicity, household income, having a child with a chronic condition, having a child aged $0-5$ years). For analysis purposes, we categorized household income as low $(<\$ 30,000)$, medium $(\$ 30,000-\$ 60,000)$, or high $(>\$ 60,000)$, consistent with prior work [21]. For certain analyses, parents were categorized into 3 groups based on pediatric portal availability and use: (1) parents with a portal option who set up a portal for their child(ren); (2) parents with a portal option who did not set up a portal for their child(ren); and (3) parents who do not have the option, or do not know whether they have the op- 
tion, of setting up a portal for their child(ren). For reporting results related to parental concerns with patient portals, we focus on parents who report being "very concerned" as the subgroup most likely to have attitudes that affect their behaviors related to portal use. All analyses were conducted with Stata 10 (Stata ${ }^{\oplus}$, College Station, TX). Results are presented as unweighted frequencies and weighted proportions.

\section{Results}

Of 2,783 parents invited to participate, 1,420 completed the survey (51\% completion rate). Respondent demographics are reported in $>$ Table 1.

\subsection{Utilization of Pediatric Patient Portals among Parents}

One in five parents (21\%) reported that their child's health care practice offered the option of setting up a patient portal for their child(ren), 39\% reported their child's health care practice did not offer the option, and 40\% were unsure. Among the 306 parents given the option, 59\% reported setting up a portal for their child, which reflects $12 \%$ of the total sample. Parents who set up a patient portal for their child(ren) did not differ from those who did not set up a portal or those who did not have or know of the option to set up a portal based on parent race/ethnicity, household income level, having a child with a chronic condition, or having $\geq 1$ child aged $0-5$ years.

Among the 133 parents who reported that they had the option but had not set up a patient portal for their child, the most common reasons cited were no time (28\%), no need for patient portal (27\%), and not knowing it needed to be set up (22\%). Among the 18 "other" reasons for not setting up a portal (e.g., portal is new, difficulty setting up the portal, not getting around to setting up the portal), no single reason was cited by more than 3 parents. Only one was related to privacy concerns. Parents' reasons for not setting up a portal for their child were not significantly associated with parent race/ethnicity, having a child with a chronic condition, or having $\geq 1$ child aged $0-5$ years. The distribution of reasons for not setting up a portal did differ by household income level $(\mathrm{p}<.002)$; the most common reason given by parents in high-income households was no time (35\%), while for parents in medium-income households it was no need for patient portal (40\%) and for parents in low-income households it was not knowing that it needed to be set up (33\%).

Among the 173 parents who reported setting up a portal for their child, $>$ Table 2 presents their use of the portal for business and patient care tasks. Similar proportions of parents report using portals for business tasks (ranging from $41 \%$ to $50 \%$ ); greater variation was seen in the use of portals for patient care tasks (ranging from $29 \%$ to $61 \%$ ), with more use for viewing lab results or immunization records, and less use to request referrals and obtain prescription refills. No significant patterns in current use were observed by parent demographic characteristics.

For the 1,102 parents who did not have or know of an option to set up a portal, $>$ Table 2 presents their likelihood of using a portal in the future to conduct business and patient care tasks. Similar proportions of parents report that they would use the portal for business tasks if given the option (45-48\%) as parents who currently use portals; however, more variation was seen when comparing patient care tasks among parents' future and current use. Almost twice as many parents indicate that they would use the portal if given the option for certain patient care tasks, such as to request refills and referrals, than parents who currently use portals.

Exploring patterns in projected future uses by key parent demographics, likelihood of future patient portal use did not differ significantly by parent race/ethnicity or household income. However, parents of children with chronic conditions were more likely than parents of children without chronic conditions to report being "very likely" to use patient portals to schedule an appointment ( $50 \%$ vs. $42 \%, \mathrm{p}<0.05$ ), request reminders about upcoming appointments ( $51 \%$ vs. $42 \%$, p $<0.05$ ), request reminders to schedule an appointment or immunization ( $53 \%$ vs. $44 \%, \mathrm{p}<0.05)$, see/print immunization records ( $58 \%$ vs. $50 \%, \mathrm{p}<0.05)$, request prescription refills $(57 \%$ vs. $45 \%, \mathrm{p}<0.05)$, view results of their child's lab tests $(60 \%$ vs. $49 \%$, p < 0.05$)$, and request referrals for their child $(54 \%$ vs. $40 \%, \mathrm{p}<0.01)$. 
In addition, parents with $\geq 1$ child $0-5$ years were more likely than parents of older children to report being "very likely" to use the portal to see/print a copy of the child's immunization record (58\% vs. $50 \%, \mathrm{p}<0.05)$.

\subsection{Parental Concerns about Pediatric Patient Portals}

With regard to the potential concern that someone could hack into the portal system and see a child's personal health information, $31 \%$ of respondents were very concerned, $39 \%$ were somewhat concerned, and $30 \%$ were not concerned. About 1 in 4 respondents $(27 \%)$ were very concerned that there could be a greater chance of errors if a child did not see the doctor in person, while $43 \%$ were somewhat concerned and $30 \%$ were not concerned. For the potential concern that it would take too long to get a response to questions/requests, $24 \%$ of respondents were very concerned, $45 \%$ were somewhat concerned, and 31\% were not concerned. Finally, 19\% were very concerned that they would not know which staff member was answering their questions, while $41 \%$ were somewhat concerned and $40 \%$ were not concerned.

As shown in Table 3, parents' level of concern regarding patient portals varied by their portal status. Parents who did not have or know of a portal option were more likely than those who chose not to set up a portal and those who did set up a portal to report being "very concerned" across the 4 potential concerns listed in the survey.

Parents' level of concern regarding patient portals did not vary by whether they have a child with a chronic condition or $\geq 1$ child aged $0-5$ years, but did differ by parent race/ethnicity and household income. For all concerns listed, Black, non-Hispanic parents and parents in low-income households were most likely, and White, non-Hispanic parents and parents in high-income households least likely, to be "very concerned".

\section{Discussion}

This national study illustrates that despite the recent proliferation of EHRs associated with the federal HITECH and Meaningful Use Incentive Program, patient portals are not currently a significant mode of parent-provider interactions in the pediatric setting. Our findings indicate that, as of June $2013,39 \%$ of US parents did not have the option of setting up a patient portal for their children and $40 \%$ were unsure whether they had this option; only $12 \%$ of US parents had set up a patient portal for their child. These findings indicate that there is significant room for growth in pediatric portal availability and that education is needed to more broadly advertise this option where it is available. More encouraging is the finding that among parents with the option of a patient portal, $59 \%$ had set up a portal for their child, which is higher than some prior reports [10,15] and on par with one study of parents of chronically ill children [9].

We hypothesized that non-White and lower-income parents would be less likely to use patient portals based on prior reports for adult [8] and pediatric [10, 13, 15] patients, while parents of children with a chronic condition and parents of younger children would be more likely to use patient portals $[9,10]$. However, we found no difference in any of these characteristics when comparing parents who set up a portal for their child with those who chose not to set up a portal and those who did not have or know of a portal option for their children. We also found no differences in current uses of pediatric portals by these parent demographics.

We did find differences in reasons for not setting up a portal by household income level, and Black, non-Hispanic parents and low-income households were most likely to be very concerned about potential portal issues. Projected uses among parents who did not have or know of a portal option differed by whether the parent had at least one child with chronic condition or aged 5 years or less.

Our findings offer insights into how portals are likely to be used by parents as they become more broadly available. We found that areas of current use by parents who have already established a portal for their child closely mirrored areas deemed likely for future use as rated by parents who have not yet had the opportunity to set up a portal. The proportion of parents who reported current use of a portal for a range of business tasks (e.g., scheduling appointments) was remarkably consistent with 
the proportion predicting likely future use (between $41 \%$ and 50\%), suggesting that even without direct experience, a segment of the parent population envisions interacting electronically with their child's health care provider. The proportion reporting current or likely future use of a portal for patient care tasks was more variable, but in a logical way: the most-endorsed current or future use was for brief informational activities such as obtaining a copy of the immunization record. Where current use was reported at a level lower than likely future use (request a referral or a prescription refill), it is plausible that many current portal users have not yet encountered a clinical need for these services.

This study also suggests that a segment of the parent population does not intend to use patient portals to interact with their child's health care provider. The responses regarding portal use were consistent between those who had already set up a portal for their child's provider versus those who had no opportunity to set up a portal (and thus were predicting future use), despite the finding that the no-portal-option group expressed concern about various aspects of portals at roughly 3 times the rate of the current-portal group. However, even that higher rate was relatively minor, as no single area of concern was endorsed by more than one third of parents. Moreover, there was no consistent association between lack of current or future portal use and parent demographic characteristics. Also, parents who had the option but chose not to set up a portal typically endorsed disinterest or lack of need as their reasons, rather than a particular criticism or concern about portals. These parents expressed lower levels of concern than parents who did not have or know of a portal option, possibly indicating that portal concerns may be ameliorated with increased knowledge about patient portals.

The Centers for Medicare and Medicaid Services (CMS) specify the criteria that providers must meet for the Meaningful Use Incentive Program. Stage 1 criteria, which began in 2011, include the ability for patients to access their electronic health records. Stage 2 criteria include sending secure electronic messages between providers and patients and allowing patients to access their own health information via a secure portal. To meet Stage 2 incentive criteria, providers must demonstrate that a certain proportion of their patient population is engaging in these aspects of meaningful use. Based on the results of this study, child health providers should expect that roughly half of their parents have positive views about utilizing patient portals; the other half of parents may be disinclined to engage via portals. Even if providers make substantial efforts to promote portal use among parents and offer technical support to assist parents in setting up portals, it is likely that they will need to continue offering business and patient care services through current means. As a consequence, practices may need to concurrently maintain several mechanisms for preventive care reminders and other communications. At the same time, practices' EHR systems will be required to track patient preferences for communications, which have been demonstrated to vary widely [22].

\subsection{Limitations}

There are several limitations to this study. Availability and use of patient portals were reported by parents but not verified with their child's health care provider. We did not track portal use over time to evaluate the trajectory of portal use over time and across the child age span. In addition, the scope of this survey was to explore parents' perspectives on patient portal use for their children; we were not able to include the perspectives of adolescents, who may access their own portal information and for whom parents may have limited or no access to their portal information. Also, projected use of patient portals by persons who do not yet have portal access may not accurately reflect how they would actually use a portal once provided with portal access. Our findings do not take into account that available functionality may differ across patient portal platforms.

Because the level of pediatric portal use by parents may have increased and types of uses may have changed since this survey was administered, future studies should continue to track pediatric portal uptake and facilitators and barriers to portal use. Also, exploration of additional parent characteristics, knowledge, attitudes, and preferences of those not engaging in pediatric portals will be helpful for targeting efforts to encourage portal adoption and sustained use. 


\section{Conclusion}

In conclusion, this national study indicates that parental use of patient portals to interact with child health providers is currently low, but that about half of parents perceive value in using portals to conduct routine business tasks and certain patient care interactions with their child's health care provider. However, providers cannot assume that all parents will embrace portals, and thus will need to concurrently support traditional communication mechanisms to reach their entire patient population.

\section{Clinical Relevance Statement}

This study demonstrates that many parents may not be interested in using patient portals for their children's health care, which may be a barrier for pediatric health care providers who want to qualify for federal Meaningful Use financial incentives.

\section{Conflicts of Interest}

The authors declare they have no conflicts of interest in the research.

\section{Protection of Human and Animal Subjects}

The study was approved by the University of Michigan Medical School Institutional Review Board.

\section{Acknowledgements}

This work was supported by the Centers for Disease Control and Prevention (U01 IP000316). The findings and conclusions are those of the authors, and do not represent an official viewpoint of the Centers for Disease Control and Prevention. 
Table 1 Demographic Characteristics of Parent Respondents $(\mathrm{N}=1,420)$

\begin{tabular}{|c|c|c|}
\hline Parent Characteristic & $\begin{array}{l}\mathrm{N} \\
\text { (unweighted) }\end{array}$ & $\begin{array}{l}\% \\
\text { (weighted) }\end{array}$ \\
\hline \multicolumn{3}{|l|}{ Gender } \\
\hline Male & 643 & 44 \\
\hline Female & 777 & 56 \\
\hline \multicolumn{3}{|l|}{ Race/ethnicity } \\
\hline White, non-Hispanic & 1045 & 63 \\
\hline Black, non-Hispanic & 101 & 12 \\
\hline Hispanic & 172 & 17 \\
\hline Other, non-Hispanic & 102 & 8 \\
\hline \multicolumn{3}{|l|}{ Household income } \\
\hline Low $<\$ 30,000$ & 227 & 19 \\
\hline Medium $\$ 30,000-\$ 60,000$ & 375 & 26 \\
\hline High $>\$ 60,000$ & 818 & 55 \\
\hline \multicolumn{3}{|l|}{ Has any child with chronic condition } \\
\hline$\geq 1$ child has chronic condition & 674 & 45 \\
\hline No child with chronic condition & 746 & 55 \\
\hline \multicolumn{3}{|l|}{ Has any child aged $0-5$ years } \\
\hline$\geq 1$ child $0-5$ years & 570 & 43 \\
\hline No child $0-5$ years (all aged $6-17$ years) & 850 & 57 \\
\hline \multicolumn{3}{|c|}{ Practice setting for child's routine health care } \\
\hline Private office with $1-2$ doctors & 405 & 30 \\
\hline Private office with $\geq 3$ doctors & 599 & 39 \\
\hline Community health center or public clinic & 97 & 8 \\
\hline Hospital-affiliated doctor's office or clinic & 190 & 13 \\
\hline HMO clinic & 60 & 4 \\
\hline Urgent care center & 16 & 2 \\
\hline Other setting & 19 & 1 \\
\hline No routine care & 26 & 2 \\
\hline
\end{tabular}


Table 2 Parental Use of Patient Portals for Their Child

\begin{tabular}{|l|l|l|}
\hline Type of Use & $\begin{array}{l}\text { Current Use, Par- } \\
\text { ents who Set Up } \\
\text { Portal } \\
\text { weighted \% (un- } \\
\text { weighted N=173) }\end{array}$ & $\begin{array}{l}\text { Likelihood of Future } \\
\text { Use, Parents Not } \\
\text { Given Portal Option } \\
\text { weighted \% (un- } \\
\text { weighted N=1102) }\end{array}$ \\
\hline Business Tasks & 49 & 46 \\
\hline Schedule an appointment for your child & 47 & 45 \\
\hline Update your contact or insurance information & 50 & 46 \\
\hline Request reminders about child's upcoming appointment & 41 & 48 \\
\hline $\begin{array}{l}\text { Request reminders that it's time to schedule child's next } \\
\text { appointment or immunization }\end{array}$ & & 38 \\
\hline Patient Care Tasks & 39 & 54 \\
\hline Get advice regarding child's minor illness/injury & 56 & 50 \\
\hline See/print a copy of child's immunization record & 29 & 54 \\
\hline Request a prescription refill for your child & 61 & 46 \\
\hline See results of your child's lab tests & 28 & \\
\hline Request a referral for your child & & \\
\hline
\end{tabular}

Table 3 Concerns Regarding Patient Portals by Parents' Portal Status*

\begin{tabular}{|c|c|c|c|}
\hline \multirow[b]{2}{*}{ Portal Concern } & \multicolumn{3}{|c|}{ Proportion "Very Concerned" (weighted \%) } \\
\hline & $\begin{array}{l}\text { Parents who Do Not } \\
\text { Have or Know of } \\
\text { Portal Option (un- } \\
\text { weighted } \mathrm{N}=1102 \text { ) }\end{array}$ & $\begin{array}{l}\text { Parents who Did Not } \\
\text { Set Up Portal (un- } \\
\text { weighted } N=133 \text { ) }\end{array}$ & $\begin{array}{l}\text { Parents who Set Up } \\
\text { Portal (unweighted } \\
N=173 \text { ) }\end{array}$ \\
\hline $\begin{array}{l}\text { Someone could hack into the } \\
\text { system and see my child's } \\
\text { personal health information }\end{array}$ & $36 \%$ & $20 \%$ & $10 \%$ \\
\hline $\begin{array}{l}\text { There's a greater chance of er- } \\
\text { rors if my child does not see } \\
\text { the doctor in person }\end{array}$ & $31 \%$ & $20 \%$ & $9 \%$ \\
\hline $\begin{array}{l}\text { It may take too long to get a } \\
\text { response to my questions or } \\
\text { requests }\end{array}$ & $27 \%$ & $8 \%$ & $11 \%$ \\
\hline $\begin{array}{l}\text { I would not know which } \\
\text { member of the office staff is } \\
\text { answering my question }\end{array}$ & $21 \%$ & $11 \%$ & $9 \%$ \\
\hline
\end{tabular}

${ }^{*} p \leq .0001$ for all comparisons across parents groups. 


\section{References}

1. Health Information Technology for Economic and Clinical Health (HITECH) Act, 42 USC $\$ \$ 13001-13424$ (2009). Available at: http://www.healthit.gov/sites/default/files/hitech_act_ex cerpt_from_arra_with_index.pdf. Accessed: October 22, 2014.

2. Centers for Medicare \& Medicaid Services (CMS). Electronic Health Record Incentive Program-Stage 2, Final Rule. Fed Regist 2012; 77(171): 53968-54162. Available at: http://www.gpo.gov/fdsys/pkg/ FR-2012-09-04/pdf/2012-21050.pdf. Accessed: October 22, 2014.

3. National Learning Consortium. Fact sheet: how to optimize patient portals for patient engagement and meet Meaningful Use requirements. May 2013. Available online at: http://www.healthit.gov/sites/default/ files/nlc_how_to_optimizepatientportals_for_patientengagement.pdf. Accessed: October 22, 2014.

4. Office of the National Coordinator for Health Information Technology (ONC). What is a patient portal? Available at: http://www.healthit.gov/providers-professionals/faqs/what-patient-portal. Accessed December 19, 2014.

5. Goel MS, Brown TL, Williams A, Cooper AJ, Hasnain-Wynia R, Baker DW. Patient reported barriers to enrolling in a patient portal. J Am Med Inform Assoc 2011; 18(Suppl. 1): i8-i12.

6. Ancker JS, Barrón Y, Rockoff ML, Hauser D, Pichardo M, Szerencsy A, Calman N. Use of an electronic patient portal among disadvantaged populations. J Gen Intern Med 2011; 26(10): 1117-1123.

7. Wakefield DS, Kruse RL, Wakefield BJ, Koopman RJ, Keplinger LE, Canfield SM, Mehr DR. Consistency of patient preferences about a secure internet-based patient communications portal: contemplating, enrolling, and using. Am J Med Qual 2012; 27(6): 494-502.

8. Goldzweig CL, Orshansky G, Paige NM, Towfigh AA, Haggstrom DA, Miake-Lye I, Beroes JM, Shekelle PG. Electronic patient portals: evidence on health outcomes, satisfaction, efficiency, and attitudes: a systematic review. Ann Intern Med 2013; 159(10): 677-687.

9. Tom JO, Mangione-Smith R, Solomon C, Grossman DC. Integrated personal health record use: association with parent-reported care experiences. Pediatrics 2012; 130(1): e183-e190.

10. Byczkowski TL, Munafo JK, Britto MT. Variation in use of Internet-based patient portals by parents of children with chronic disease. Arch Pediatr Adolesc Med 2011; 165(5): 405-411.

11. Britto MT, Hesse EA, Kamdar OJ, Munafo JK. Parents' perceptions of a patient portal for managing their child's chronic illness. J Pediatr 2013; 163(1): 280-281.e2.

12. Britto MT, Jimison HB, Munafo JK, Wissman J, Rogers ML, Hersh W. Usability testing finds problems for novice users of pediatric portals. Pediatr Adolesc Med 2009; 16(5): 660-669.

13. Byczkowski TL, Munafo JK, Britto MT. Family perceptions of the usability and value of chronic disease web-based patient portals. Health Informatics J 2014; 20(2): 151-162.

14. Nagykaldi Z, Aspy CB, Chou A, Mold JW. Impact of a wellness portal on the delivery of patient-centered preventive care. J Am Board Fam Med 2012; 25(2): 158-167.

15. Ketterer T, West DW, Sanders VP, Hossain J, Kondo MC, Sharif I. Correlates of patient portal enrollment and activation in primary care pediatrics. Acad Pediatr 2013; 13(3): 264-271.

16. National Poll on Children's Health. Available at: http://mottnpch.org/. Accessed October 22, 2014.

17.GfK. KnowledgePanel ${ }^{\bullet}$ design summary. 2013. Available at: http://www.knowledgenetworks.com/knpa nel/docs/knowledgepanel\%28R\%29-design-summary-description.pdf. Accessed December 19, 2014.

18. Hashikawa AN, Brousseau DC, Singer DC, Gebremariam A, Davis MM. Emergency department and urgent care for children excluded from child care. Pediatrics 2014; 134(1): e120-e127.

19. Hanauer DA, Zheng K, Singer DC, Gebremariam A, Davis MM. Public awareness, perception and use of online physician rating sites. JAMA 2014; 311(7): 734-735.

20. Woolford SJ, Clark SJ, Butchart A, Geiger JD, Davis MM, Fagerlin A. To pay or not to pay: Public perception regarding insurance coverage of obesity treatment. Obesity 2013; 21(12): E709-E714.

21.Leo HL, Clark SJ, Butchart AT, Singer DC, Clark NM, Davis MM. 2009 seasonal and H1N1 influenza vaccination compliance in asthmatic children and adults. J Allergy Clin Immunol 2010; 126(1): 166-168.

22.Zhao Z, Luman ET. Progress toward eliminating disparities in vaccination coverage among U.S. children, 2000-2008. Am J Prev Med 2010; 38(2): 127-137.

23. Clark SJ, Reeves SL, Gebremariam A, Stokley S, Dombkowski KJ. Communication from primary care practices regarding adolescent immunization. Clin Pediatr Published online November 10, 2014. DOI: $10.1177 / 0009922814557787$. 